\title{
Hydrothermal Upgrading of Korean MSW for Solid Fuel Production: Effect of MSW Composition
}

\author{
Daegi Kim, Pandji Prawisudha, and Kunio Yoshikawa \\ Department of Environmental Science and Technology, Tokyo Institute of Technology, G5-8, 4259 Nagatsuta-cho, \\ Midori-ku, Yokohama 226-8503, Japan \\ Correspondence should be addressed to Daegi Kim, daegi.k.aa@m.titech.ac.jp
}

Received 1 November 2011; Revised 3 January 2012; Accepted 27 January 2012

Academic Editor: Panagiotis Grammelis

Copyright ( 2012 Daegi Kim et al. This is an open access article distributed under the Creative Commons Attribution License, which permits unrestricted use, distribution, and reproduction in any medium, provided the original work is properly cited.

In Korea, municipal solid waste (MSW) treatment is conducted by converting wastes into energy resources using the mechanicalbiological treatment (MBT). The small size MSW to be separated from raw MSW by mechanical treatment (MT) is generally treated by biological treatment that consists of high composition of food residue and paper and so forth. In this research, the hydrothermal treatment was applied to treat the surrogate MT residue composed of paper and/or kimchi. It was shown that the hydrothermal treatment increased the calorific value of the surrogate MT residue due to increasing fixed carbon content and decreasing oxygen content and enhanced the dehydration and drying performances of kimchi. Comparing the results of paper and kimchi samples, the calorific value of the treated product from paper was increased more effectively due to its high content of cellulose. Furthermore, the change of the calorific value before and after the hydrothermal treatment of the mixture of paper and kimchi can be well predicted by this change of paper and kimchi only. The hydrothermal treatment can be expected to effectively convert high moisture MT residue into a uniform solid fuel.

\section{Introduction}

In recent years, the global issue in the energy field is that with the combination of increasing energy consumption and the steady depletion of fossil fuel reserves, coal can only be used to last 122 years on the basis of the 2008 production rate. This, together with the global environmental issues of the appropriate treatment of increasing municipal solid waste (MSW) has prompted a global research to develop alternative energy resources as well as to reduce $\mathrm{CO}_{2}$ emissions by using renewable energy from biomass and waste [1-3]. Korean government has had an interest to employ a new MSW treatment system, namely, the mechanical biological treatment (MBT) system. The MBT system concepts for waste processing evolved in Germany and incorporated two stages of mechanical treatment (MT) and biological treatment (BT). The bigger size MSW separated by the mechanical treatment (MT) as combustible matter is processed to $\mathrm{RDF}$ (refuse derived fuel) for energy generation, while the separated MSW after MT (MT residue) is used for producing organic fertilizer and biogas $\left(\mathrm{CH}_{4}\right)$ by employing the BT stage. The MBT system enables us to circulate resources and to reduce the greenhouse gas emissions, while getting the profit by making renewable resource fuels from MSW [2] to reduce the quantity of waste sent to landfill and to increase the potential recovery of resources. This system acts as a pretreatment system for the next step of processing $[3,4]$.

However, in the MBT system, the BT stage has common problems requiring long treatment time, more than 1 week to 1 month, with unpleasant smells $[5,6]$. Especially, food residues in Korea are inappropriate for composting due to the high salinity from food residue such as kimchi, which are fermented and stored in highly saline water [5].

The hydrothermal treatment is one of the thermochemical processes, treating waste in high-temperature and highpressure water media to upgrade the material in a short time [7-10]. That is one of progressive technologies for converting MSW and biomass into useful energy resources because it can improve the dehydration and drying performances of high moisture content biomass as well as upgrade the property of the fuel produced from MSW. 


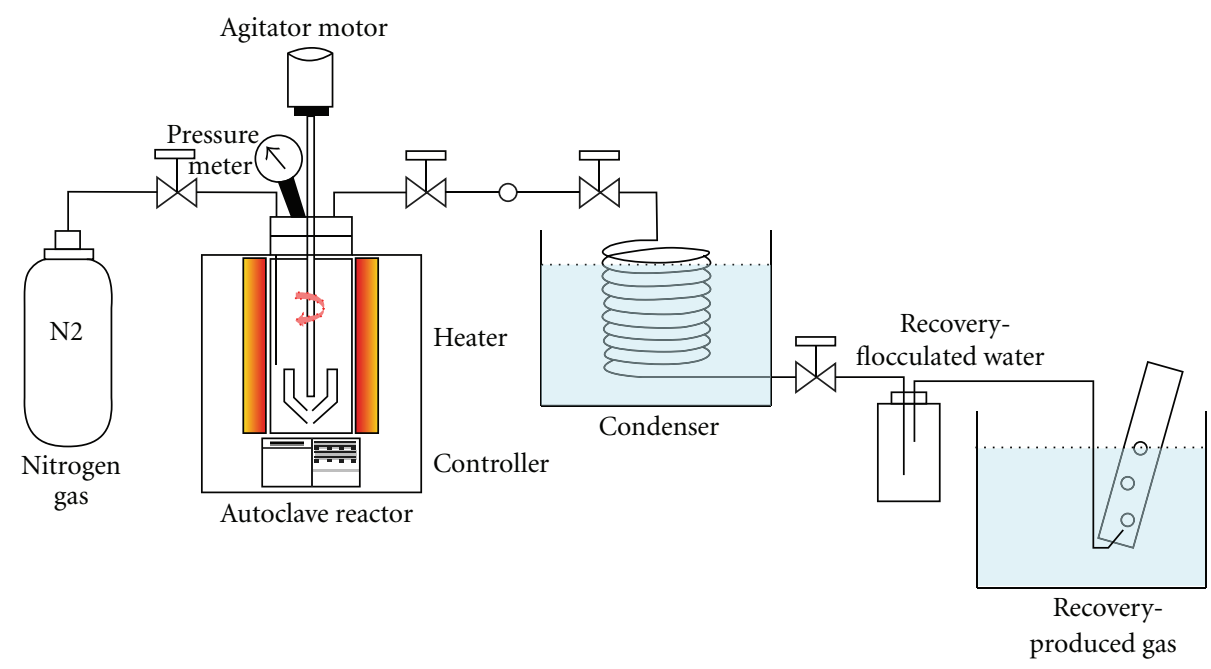

FIgURE 1: Schematic diagram of the autoclave facility.

TABLE 1: Biomass composition of paper and kimchi.

\begin{tabular}{lccc}
\hline $\begin{array}{l}\text { Biomass composition (wt. } \\
\text { \%), (d.b) }\end{array}$ & Paper & Kimchi & $\begin{array}{c}\text { Calorific value } \\
\text { (MJ/kg), (d.b) }\end{array}$ \\
\hline Cellulose & 57.26 & 16.78 & 16.5 \\
Hemicellulose & 6.95 & 0.51 & $16.7[23]$ \\
Lignin & 12.28 & 4.64 & 20.4 \\
Others and Ash & 23.51 & 78.07 & - \\
\hline
\end{tabular}

d.b: dry basis.

MSW differs in quality and quantity depending on the policy and culture of the nation. The composition of MSW should be different according to seasons and sectors and affected by custom, living style, and so forth as well as regulation of the country. Separated MSW by MT in Korea was usually consisted of high food residue (40-50\%), paper (30-40\%), plastic, and so forth. Therefore, it has high moisture content of about $50-60 \%$ since the food residue affects the moisture content and major properties of MSW. Especially, Korean food residue has had high moisture and high salinity to affect the treatment solution. Its property should provide a negative product to treat MT residue in BT stage. If we want to utilize the MT residue as a solid fuel together with RDF the MT residue should be dehydrated, dried, upgraded, and compacted.

In this research, a mild reaction condition of subcritical water $\left(180^{\circ} \mathrm{C}<T<220^{\circ} \mathrm{C}, 1.8 \mathrm{MPa}<P<2.4 \mathrm{MPa}\right)$ is employed in the hydrothermal treatment, focused on its effects on the surrogate MT residue (kimchi, paper, and their mixture). The aim of the present work is to demonstrate the improvement of the dehydration and drying performances and upgrading of solid products of surrogate MT residue in a short time and to make uniform solid fuel using the hydrothermal treatment.

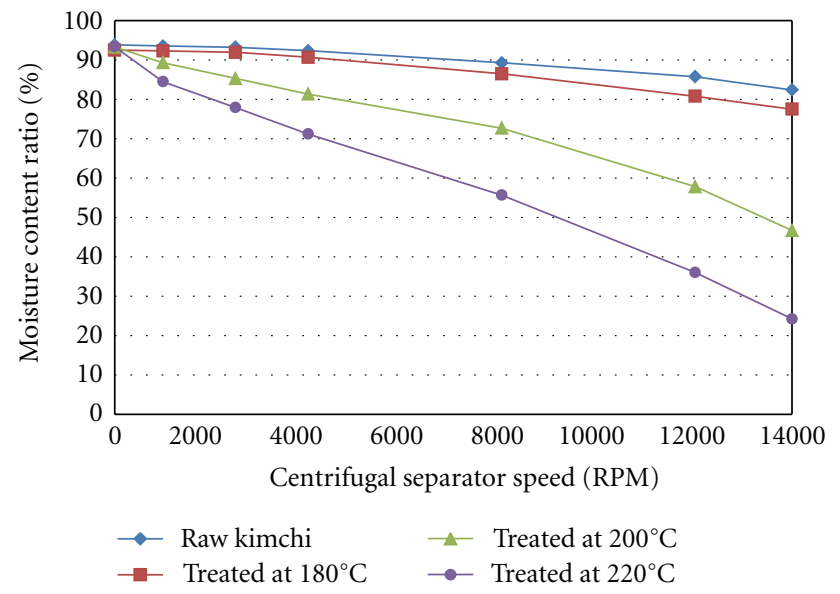

FIGURE 2: Dehydration performance of raw kimchi and its hydrothermal products.

\section{Operation Principle of the Hydrothermal Treatment}

The hydrothermal treatment employed in this research is utilized using high-temperature water to treat the raw material. Solid wastes are fed into the reactor, and then, about $200^{\circ} \mathrm{C}, 2 \mathrm{MPa}$ saturated steam is supplied into the reactor for about 30 minutes and the blades are installed inside the reactor to mix the wastes for about 30-90 minutes. Then steam inside of the reactor will be discharged, condensed, and treated to be utilized as the boiler feed water again. The product is powder-like substance, and the moisture content is higher than the raw material, but it shows much improved dehydration and drying performances than the raw material. The hydrothermal reactions include the hydration, hydrous pyrolysis and decarboxylation, and so 
TABLE 2: Proximate and ultimate analysis results of paper and kimchi and their products.

\begin{tabular}{|c|c|c|c|c|c|c|c|c|}
\hline & \multicolumn{4}{|c|}{ Paper } & \multicolumn{4}{|c|}{ Kimchi } \\
\hline & $\begin{array}{c}\text { Raw } \\
\text { material }\end{array}$ & $\begin{array}{c}\text { Treated at } \\
180^{\circ} \mathrm{C}\end{array}$ & $\begin{array}{c}\text { Treated at } \\
200^{\circ} \mathrm{C}\end{array}$ & $\begin{array}{l}\text { Treated at } \\
220^{\circ} \mathrm{C}\end{array}$ & $\begin{array}{c}\text { Raw } \\
\text { material }\end{array}$ & $\begin{array}{c}\text { Treated at } \\
180^{\circ} \mathrm{C}\end{array}$ & $\begin{array}{l}\text { Treated at } \\
200^{\circ} \mathrm{C}\end{array}$ & $\begin{array}{l}\text { Treated at } \\
220^{\circ} \mathrm{C}\end{array}$ \\
\hline Moisture (a.r) & 2.3 & 4.0 & 4.2 & 6.5 & 92.4 & 93.8 & 93.2 & 93.3 \\
\hline \multicolumn{9}{|l|}{ Proximate analysis (d.b) } \\
\hline Volatile matter & 87.0 & 76.2 & 58.4 & 56.6 & 67.1 & 60.3 & 60.9 & 57.8 \\
\hline Fixed carbon & 5.3 & 14.1 & 27.0 & 29.2 & 22.6 & 29.8 & 29.7 & 31.0 \\
\hline Ash & 7.7 & 9.7 & 14.6 & 14.2 & 10.3 & 10.0 & 9.4 & 11.3 \\
\hline \multicolumn{9}{|l|}{ Ultimate analysis (wt. \%) (d.a.f.) } \\
\hline $\mathrm{C}$ & 40.3 & 45.0 & 54.5 & 54.8 & 33.6 & 34.4 & 35.8 & 37.0 \\
\hline $\mathrm{H}$ & 5.6 & 5.4 & 5.0 & 4.8 & 5.3 & 4.6 & 4.6 & 4.5 \\
\hline $\mathrm{N}$ & 0.2 & 0.1 & 0.4 & 0.2 & 3.5 & 3.2 & 3.2 & 3.0 \\
\hline $\mathrm{O}$ & 53.8 & 49.5 & 40.1 & 40.2 & 57.6 & 57.8 & 56.4 & 55.4 \\
\hline \multicolumn{9}{|l|}{$\begin{array}{l}\text { Composition of biomass (wt. \%), } \\
\text { (d.b) }\end{array}$} \\
\hline Cellulose & 57.3 & 41.0 & 41.3 & 36.2 & 16.8 & 11.5 & 11.1 & 9.5 \\
\hline Hemicellulose & 7.0 & 0.8 & 0.8 & 0.5 & 0.5 & 0.1 & 0.1 & 0.0 \\
\hline Lignin & 12.3 & 13.6 & 14.1 & 14.7 & 4.6 & 4.9 & 4.9 & 5.0 \\
\hline Other and ash & 23.5 & 44.6 & 43.9 & 48.6 & 78.1 & 83.5 & 84.0 & 85.5 \\
\hline Weight loss (wt. \%), (d.b) & & 9.5 & 16.3 & 20.6 & & 5.6 & 8.4 & 11.2 \\
\hline Calorific value (MJ/kg) (d.b) & 15.5 & 16.9 & 21.4 & 21.7 & 14.7 & 14.7 & 16.0 & 15.8 \\
\hline
\end{tabular}

a.r: as-received, d.b: dry basis, d.a.f: dry ash free.

on, and the reaction temperature affects the properties of hydrothermal products [8-12]. The hydrothermal treatment has benefits of no requirement of pretreatment, no emissions and lower treatment temperature compared with other thermal treatment methods such as carbonization, pyrolysis, gasification, and incineration. Moreover, the hydrothermal treatment is not only reducing the recovery costs but also environmental friendly with no usage of chemical agents [13-16]. Recently, the hydrothermal treatment has attracted interests as a possible application producing coal-like solid fuel from MSW and biomass resources with high moisture and oxygen contents [8-22].

\section{Experiment Methodology}

3.1. Apparatus and Experimental Procedure. The hydrothermal treatment experiments were performed using the $500 \mathrm{~mL}$ autoclave facility as shown in Figure 1. The autoclave facility consists of a reactor, a heater, and a steam condenser which was operated with $\mathrm{N}_{2}$ gas. For all experiments, the raw samples were milled so that their sizes become less than $1 \mathrm{~cm}$ for obtaining homogenous materials. The weight of one sample is $20 \mathrm{~g}$ which was mixed in the same amount of water and loaded into the reactor. The operating temperatures (pressures) of the hydrothermal treatment were $180^{\circ} \mathrm{C}(1.8 \mathrm{MPa}), 200^{\circ} \mathrm{C}(2.0 \mathrm{MPa})$, and $220^{\circ} \mathrm{C}(2.4 \mathrm{MPa})$, and the reaction period was 30 minutes with the agitation speed of $200 \mathrm{rpm}$. It is reported that the subcritical hydrolysis starts at proximately $180^{\circ} \mathrm{C}$ of the reaction temperature [13]. After finishing the hydrothermal reaction, the pressure

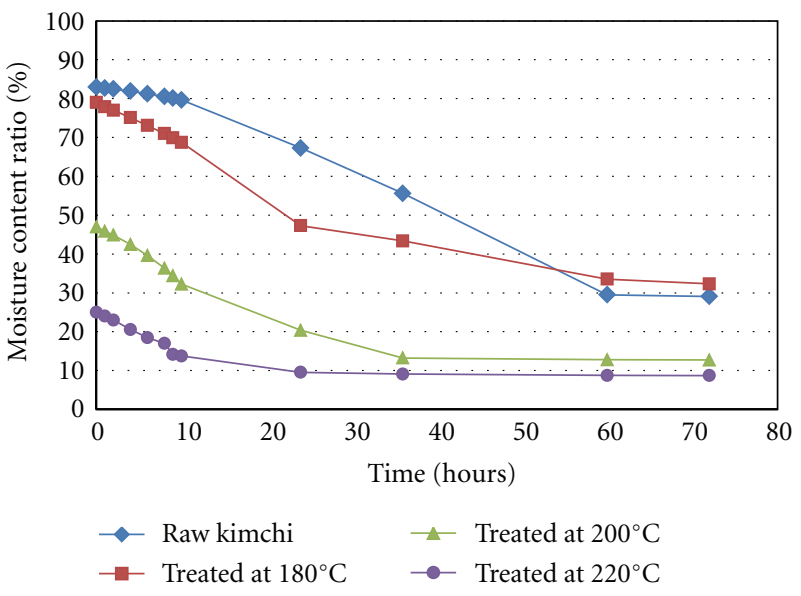

FIGURE 3: Natural drying performance of raw kimchi and, the dehydrated residue of its hydrothermal products.

and the temperature fell down to atmospheric and room temperature, and the products were taken out of the reactor.

3.2. Materials. The MT residue composition is based on the one obtained from Mokpo city, middle sized city in Republic of Korea. It is consisted of food residue (40-50\%), paper (30-40\%), plastic, wood, rubber, and others in negligible amount. In detail, the food residue is composed of various compositions such as vegetables (72\%), fruits (15\%), cereals, meat, and fish. 


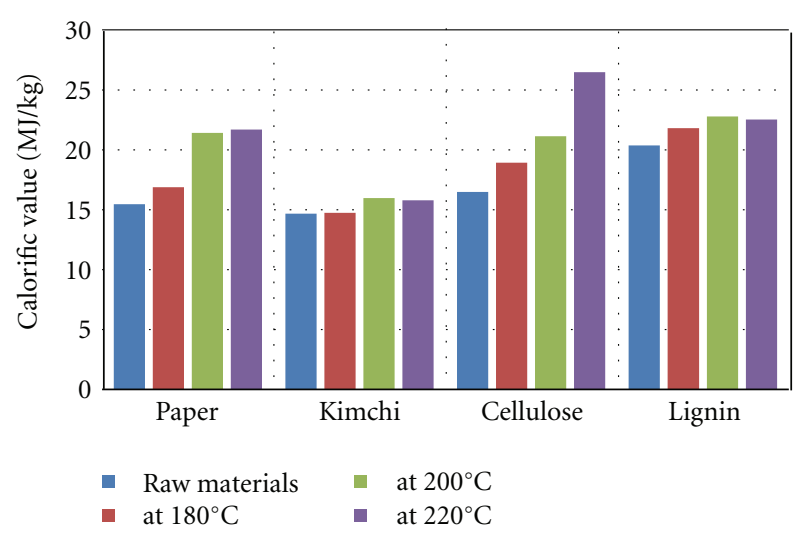

Figure 4: Effect of the hydrothermal treatment on the calorific value of products.

In this experiment, the food residue and paper contents were chosen as two parameters used, which are the highest ratio in the composition of the MT residue. Japanese newspaper and Korean kimchi in various compositions were used in substitute of paper and food residues, which were manually prepared by blending after the crushing process. In order to investigate the effect of main components in paper and kimchi, cellulose sample ( $\alpha$-Cellulose-fibriform from Nacalai Tesuque Inc., Kyoto, Japan) and lignin (Kanto Chemical Co., Inc., Japan) were also used for the hydrothermal treatment experiments.

3.3. Analysis. The dehydration performance of raw sample and hydrothermal products was determined using a centrifugal separator with variable speed from 2,000 to $14,000 \mathrm{rpm}$. The natural drying tests to evaluate the moisture content reduction of the raw materials and the hydrothermally treated products after the centrifuge dehydration were conducted in the room temperature.

The ultimate analysis of the raw samples and solid products were carried out using the PerkinElmer made 2400 Series II CHN organic elemental analyzer. The proximate analyses were conducted using the SHIMADZU D-50 simultaneous TGA/DTA analyzer. The calorific values were measured using the bomb calorimetric method according to the JIS M-8814. SEM microphotographs were taken by JSM-6610LA analytical scanning electronic microscope after drying the solid products. The biomass composition measurement of raw paper and kimchi was entrusted to Nihon Hakko Shiryo Company. The biomass composition of cellulose, hemicelluloses, and lignin was defined in (1) to (3).

$$
\begin{gathered}
\text { Hemicellulose }(\%)=\mathrm{NDF}-\mathrm{ADF}, \\
\text { Cellulose }(\%)=\mathrm{ADF}-\mathrm{ADL} \\
\text { Lignin }(\%)=\mathrm{ADL}
\end{gathered}
$$

where, NDF is neutral detergent fiber, ADF is acid detergent fiber, and ADL is acid detergent lignin.

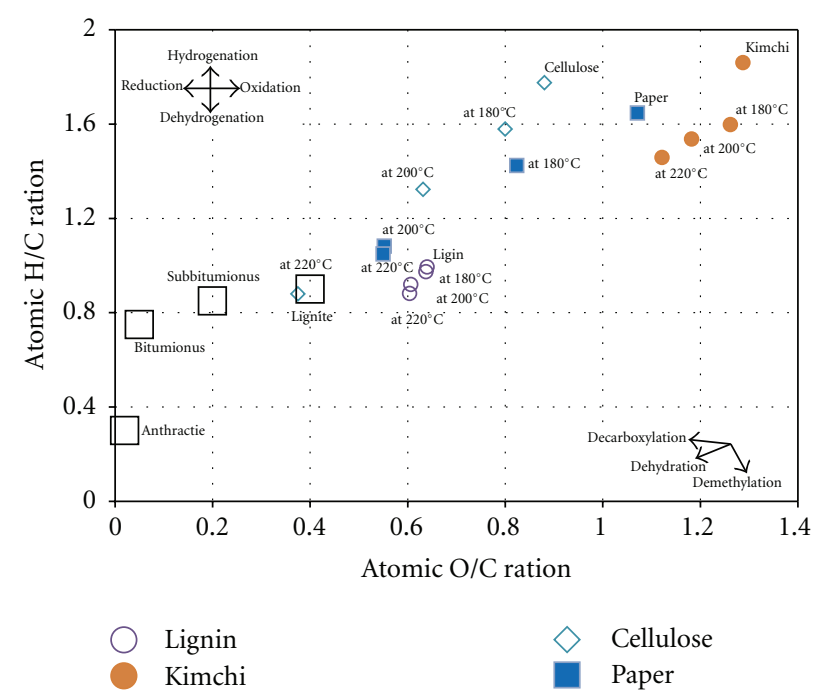

FIGURE 5: Coalification band of the paper and the kimchi at different hydrothermal reaction temperatures in comparison with cellulose, lignin and coal.

\section{Results and Discussion}

4.1. Biomass Composition of Raw Material. Table 1 shows the biomass composition of the paper and kimchi utilized in the experiments. The biomass compositions of both raw materials were completely different. The paper was composed of $57.2 \%$ cellulose, $12.3 \%$ lignin, and $6.9 \%$ hemicelluloses whose total was $76.5 \%$. The kimchi was composed of $16.8 \%$ cellulose, $4.6 \%$ lignin, and $0.5 \%$ hemicelluloses whose total is $21.9 \%$. The biomass composition of raw material should influence the property of the hydrothermal treatment product. Therefore, in this research, cellulose and lignin samples were also used to compare with the paper and the kimchi.

Table 2 shows the proximate and ultimate analysis of the paper and kimchi utilized in the experiments. The kimchi had high moisture content of $92.4 \%$, while the moisture content of paper was as low as $2.3 \%$. High-efficiency moisture removal from the MT residue is one of purposes of this research. Volatile matter content of the paper and kimchi were as high as $87.0 \%$ and $67.1 \%$, respectively, while the fixed carbon contents are low. The carbon contents in the paper and kimchi were $40.3 \%$ and $33.6 \%$, respectively. The oxygen contents in the paper and kimchi were as high as $53.8 \%$ and $57.6 \%$, respectively.

\subsection{Improvement of Dehydration and Drying Performances of} Kimchi by the Hydrothermal Treatment. Removal of moisture contents in MSW is a major target of the pretreatment, and the moisture content of MSW has a strong influence on the characteristics and treatment method of MSW [5, 20-22].

Figure 2 shows the dehydration performance of raw kimchi and its hydrothermal products treated at $180^{\circ} \mathrm{C}$, $200^{\circ} \mathrm{C}$, and $220^{\circ} \mathrm{C}$ and then dehydrated by using a centrifugal separator with various rotation speeds from 2,000 to 14,000 rpm. As shown in Table 1 and Figure 2, raw kimchi 
had $92.5 \%$ moisture content. The moisture contents of the hydrothermal products in the experiments at $180^{\circ} \mathrm{C}, 200^{\circ} \mathrm{C}$ and $220^{\circ} \mathrm{C}$ were $93.8 \%, 93.2 \%$, and $93.4 \%$, respectively.

The hydrothermal products had better dehydration performance compared with raw kimchi, and the moisture content could be reduced down to $24.2 \%$ when treated at $220^{\circ} \mathrm{C}$, with the centrifugal separator speed of $14,000 \mathrm{rpm}$. In the case of the hydrothermal treatment at $180^{\circ} \mathrm{C}$, the color of the product was changed but the result of the dehydration performance was similar to raw kimchi.

Figure 3 shows the natural drying performance of the raw kimchi and the dehydrated residue of its hydrothermal products with the centrifugal speed of $14,000 \mathrm{rpm}$ under the room temperature. It shows the time change of the moisture content of the dehydrated residue with different reaction temperatures. The moisture content of the residue treated at $200^{\circ} \mathrm{C}$ and $220^{\circ} \mathrm{C}$ decreased down to approximately $10 \%$ after 36 hours and 24 hours, respectively, while the moisture content of the raw kimchi and the dehydrated residue with the reaction temperature of $180^{\circ} \mathrm{C}$ could not be reduced below $30 \%$ by this natural drying within 70 hours.

The results clearly show that the hydrothermal treatment can improve the dehydration and drying performances of kimchi, which should lead in the reduction of energy requirement for the moisture removal from kimchi.

\subsection{Effect of the Hydrothermal Treatment on the Property of} the Products. Hydrothermal treatment breaks the physical and chemical structure in the materials such as cellulose, hemicelluloses, and lignin [10-14] in paper and kimchi, and these biomasses were broken down into smaller and simpler molecules.

Table 2 shows the property of raw samples of kimchi and paper and their products after the hydrothermal treatment which were produced at $180^{\circ} \mathrm{C}, 200^{\circ} \mathrm{C}$, and $220^{\circ} \mathrm{C}$. The chemical properties of the paper and the kimchi were changed by the hydrothermal treatment.

The paper and kimchi had high volatile matter content (87.0\% and $67.1 \%)$ and oxygen content $(53.8 \%$ and $57.6 \%)$ like other biomass. With the increase of the hydrothermal reaction temperature, the volatile matter and oxygen content decreased while the fixed carbon content increased, which were caused by the hydrolysis reaction.

Proximate and ultimate analysis of the paper and its hydrothermal products showed more significant change than the kimchi. The volatile matter of the paper decreased from $87.0 \%$ to $76.2 \%, 59.7 \%$, and $56.9 \%$ at the reaction temperature of $180^{\circ} \mathrm{C}, 200^{\circ} \mathrm{C}$, and $220^{\circ} \mathrm{C}$, respectively.

Figure 4 shows the calorific value of the paper and the kimchi before and after the hydrothermal treatment, together with those of cellulose and lignin. The calorific values of the kimchi and paper increased with the increase of the reaction temperature due to the increase of the fixed carbon content, where this calorific value increase is more significant in the case of the paper than in the case of the kimchi.

As shown in Table 1, the paper was composed of $57.3 \%$ cellulose, $12.3 \%$ lignin, $7.0 \%$ hemicelluloses, and $23.5 \%$ others and ash, while the kimchi is composed of $16.8 \%$ of cellulose, $4.6 \%$ of lignin, $0.5 \%$ of hemicelluloses, and $78.1 \%$ of other and ash. Table 2 shows biomass compositions of the hydrothermal products which were treated at $180^{\circ} \mathrm{C}, 200^{\circ} \mathrm{C}$ and $220^{\circ} \mathrm{C}$. About $40 \%$ and $60 \%$ cellulose decomposed at $200^{\circ} \mathrm{C}$ and $220^{\circ} \mathrm{C}$, respectively. About $90 \%$ and $99 \%$ hemicellulose decomposed at $180^{\circ} \mathrm{C}$ and $220^{\circ} \mathrm{C}$, respectively. Cellulose and hemicellulose were decomposed to be smaller molecular by the hydrolysis reaction in the hydrothermal treatment. However, the lignin behavior was different from cellulose and hemicellulose. When hydrothermal treated at 180 to $220^{\circ} \mathrm{C}$, less than $5 \%$ of lignin was decomposed. The results suggest that cellulose and hemicellulose were easier to decompose than lignin. As discussed elsewhere [12, 14], lignin starts to decompose at the temperature exceeding $250^{\circ} \mathrm{C}$. In addition, the hydrothermal treatment increases the calorific value of cellulose as shown in Figure 4 which explains the reason of the calorific value increase of the paper after the hydrothermal treatment whose major component is cellulose.

The hydrothermal treatment changes the properties of products like the coalification process. Figure 5 shows the coalification band of the raw materials (paper, kimchi, cellulose, and lignin) and their hydrothermal products in comparison with various kinds of coal. The hydrothermal treatment can promote water removal from waste and biomass by improving the dewatering performance as well as the chemical dehydration. The chemical dehydration significantly increases the heating value by decreasing the $\mathrm{H} / \mathrm{C}$ and $\mathrm{O} / \mathrm{C}$ ratios. The chemical dehydration of cellulose can be expressed as $4\left(\mathrm{C}_{6} \mathrm{H}_{10} \mathrm{O}_{5}\right)_{n} \leftrightarrow 2\left(\mathrm{C}_{12} \mathrm{H}_{1} \mathrm{O}_{5}\right)_{n}+10 \mathrm{H}_{2} \mathrm{O}$ where the hydrothermal reaction promotes cleavage of mainly eater and chemical bonds of cellulose.

Paper and kimchi are known to have high atomic H/C ratios and atomic $\mathrm{O} / \mathrm{C}$ ratios similar to other biomass $[10,12]$. The atomic $\mathrm{H} / \mathrm{C}$ ratio and the atomic $\mathrm{O} / \mathrm{C}$ ratio were decreased by increasing the hydrothermal reaction temperature, where the paper and the cellulose showed more significant change of the atomic $\mathrm{H} / \mathrm{C}$ ratio and the atomic $\mathrm{O} / \mathrm{C}$ ratio compared with the kimchi and the lignin and should approach to lignite characteristic by increasing the hydrothermal reaction temperature. The fuel upgrading behavior of lignin is less significant in the hydrothermal reaction temperature range from $180^{\circ} \mathrm{C}$ to $220^{\circ} \mathrm{C}$.

Figure 6 shows the SEM microphotographs of the paper and kimchi before and after the hydrothermal treatment. These SEM microphotographs reveal the changes between the raw materials and the upgraded solid products, showing disruption of physical structures and formation of individual grains in the products. Apparently, the hydrothermal treatment breaks the structure of the paper and kimchi and converts them into smaller uniform particle products.

4.4. Effect of Mixing of the Paper and Kimchi. If we can predict the effect of the hydrothermal treatment for the mixture of materials based on the hydrothermal behavior of individual material in the MT residue, it becomes much easier to evaluate the effectiveness of the hydrothermal treatment. Figures 7 and 8 show the change of the calorific value of 


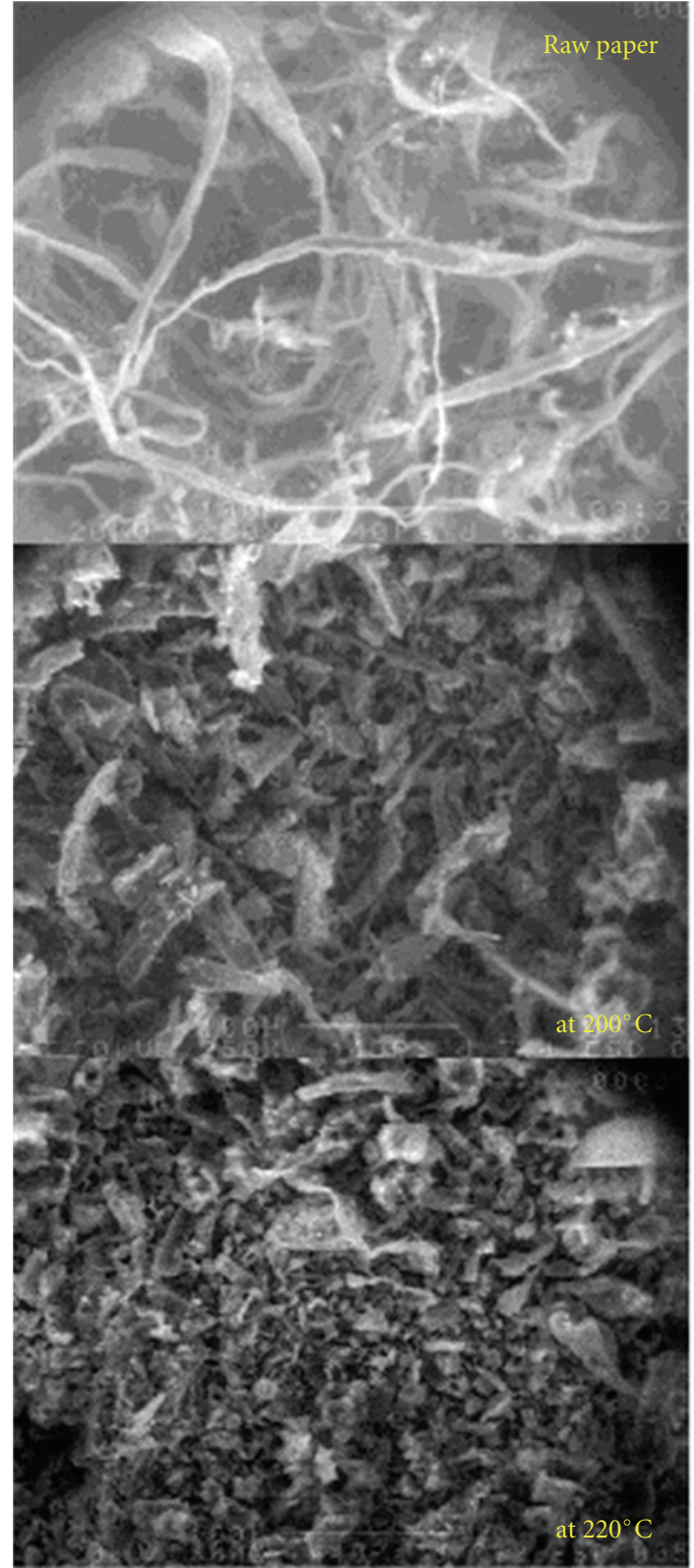

(a)

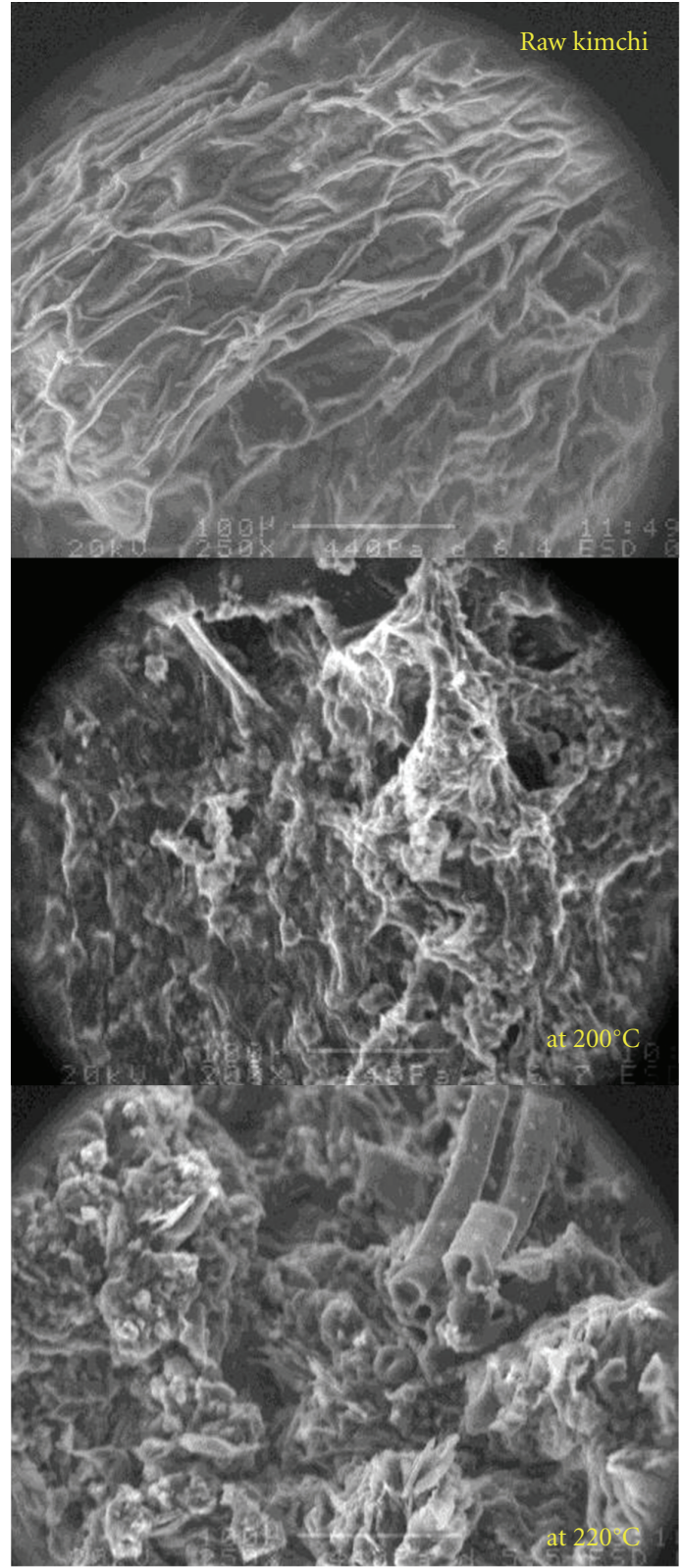

(b)

FIGURE 6: SEM microphotographs of the raw materials and their hydrothermal products; (a) paper and (b) kimchi.

the hydrothermal products by changing the mixing ratio of the paper and kimchi with various hydrothermal reaction temperatures with fixed hydrothermal reaction time of 30 minutes.

The blending ratios of paper to kimchi were from $100 \%: 0 \%$ to $0 \%: 100 \%$. In these figures, the measured calorific values of the hydrothermal products of each mixture and the predicted calorific value of the hydrothermal products by the linear interpolation of the calorific value of the hydrothermal products of the paper and kimchi showed a good agreement. From these figures, we can see that the calorific value of the hydrothermal products of the mixture of the paper and kimchi can be well predicted based on the individual hydrothermal behavior, and the fuel upgrading by the hydrothermal treatment becomes more significant by increasing the amount of the paper.

\section{Conclusion}

In this research, the hydrothermal treatment was conducted for the paper, the kimchi and their mixture surrogating the Korean MT residue to demonstrate the improvement of dehydration and drying performances as well as fuel upgrading with the reaction temperature of $180^{\circ} \mathrm{C}, 200^{\circ} \mathrm{C}$ and $220^{\circ} \mathrm{C}$, with the reaction time of 30 minutes. The dehydration and natural drying performances of the kimchi 


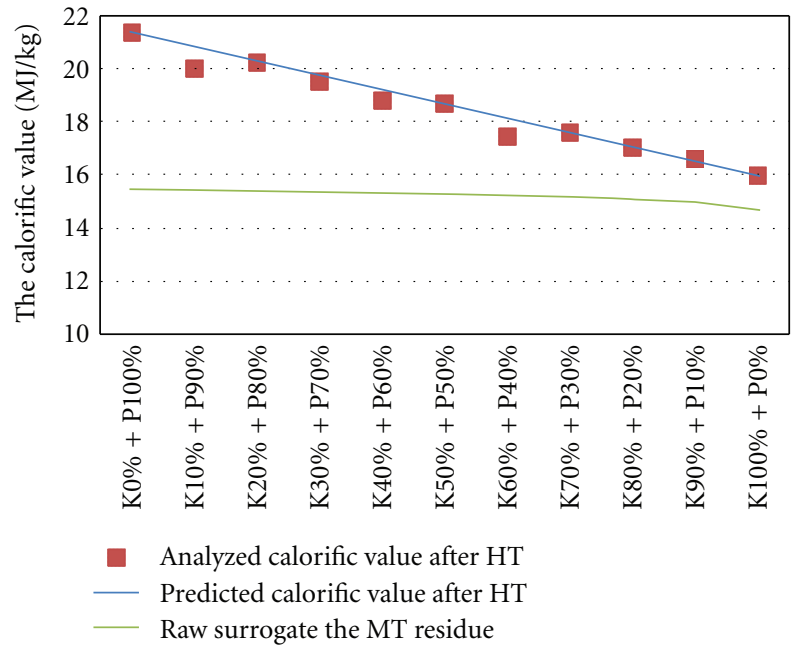

Figure 7: Change of the calorific value of the hydrothermal products by changing the mixture ratio of the paper andkimchi (hydrothermal reaction temperature $=200^{\circ} \mathrm{C}$ ).

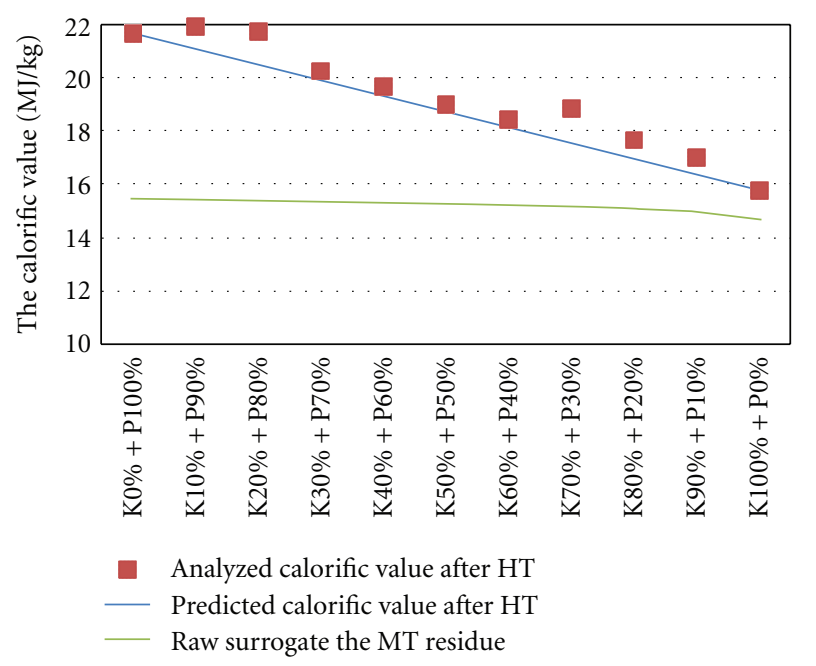

FIgURE 8: Change of the calorific value of the hydrothermal products by changing the mixture ratio of the paper and kimchi (hydrothermal reaction temperature $=220^{\circ} \mathrm{C}$ ).

were significantly improved by the hydrothermal treatment. SEM microphotography showed that the physical structure of fibers of the paper and kimchi were broken into smaller and simpler molecules by the hydrothermal treatment.

In the case of paper, the volatile matter decreased from $87.0 \%$ to $58.4 \%$ and the fixed carbon increased from $5.3 \%$ to $27.0 \%$ at the reaction temperature of $200^{\circ} \mathrm{C}$. As a result, the calorific value also increased from $14.7 \mathrm{MJ} / \mathrm{kg}$ to $21.7 \mathrm{MJ} / \mathrm{kg}$ at the reaction temperature of $200^{\circ} \mathrm{C}$. On the other hand, this fuel upgrading behavior of the kimchi was rather weak due to its low cellulose content. As for the mixture of the paper and kimchi, the fuel upgrading behavior by the hydrothermal treatment was well predicted by the individual fuel upgrading behavior of the paper and kimchi.

These results demonstrated the effectiveness of the hydrothermal treatment of the MT residue for fuel upgrading.

\section{References}

[1] Y. Kuzuhara, "Biomass Nippon strategy-why "biomass Nippon” now?” Biomass and Bioenergy, vol. 29, no. 5, pp. 331-335, 2005.

[2] Juniper Consultancy Services Ltd, "Mechanical-Biological Treatment: A Guide for Decision makers/processes, policies and markets," 2005.

[3] A. P. Economopoulos, "Technoeconomic aspects of alternative municipal solid wastes treatment methods," Waste Management, vol. 30, no. 4, pp. 707-715, 2010.

[4] R. Bayard, J. de Araújo Morais, G. Ducom, F. Achour, M. Rouez, and R. Gourdon, "Assessment of the effectiveness of an industrial unit of mechanical-biological treatment of municipal solid waste," Journal of Hazardous Materials, vol. 175, no. 1-3, pp. 23-32, 2010.

[5] Y. S. Yun, J. I. Park, and J. M. Park, "High-rate slurryphase decomposition of food wastes: indirect performance estimation from dissolved oxygen," Process Biochemistry, vol. 40, no. 3-4, pp. 1301-1306, 2005.

[6] R. Barrena, G. d'Imporzano, S. Ponsá et al., "In search of a reliable technique for the determination of the biological stability of the organic matter in the mechanical-biological treated waste," Journal of Hazardous Materials, vol. 162, no. 23, pp. 1065-1072, 2009.

[7] K. Suksankraisorn, S. Patumsawad, and B. Fungtammasan, "Co-firing of Thai lignite and municipal solid waste (MSW) in a fluidised bed: effect of MSW moisture content," Applied Thermal Engineering, vol. 30, no. 17-18, pp. 2693-2697, 2010.

[8] G. Luo, X. Cheng, W. Shi, P. James Strong, H. Wang, and W. Ni, "Response surface analysis of the water:feed ratio influences on hydrothermal recovery from biomass," Waste Management, vol. 31, pp. 438-444, 2011.

[9] J. C. Serrano-Ruiz, D. J. Braden, R. M. West, and J. A. Dumesic, "Conversion of cellulose to hydrocarbon fuels by progressive removal of oxygen," Applied Catalysis B, vol. 100, no. 1-2, pp. 184-189, 2010.

[10] A. Funke and F. Ziegler, "Hydrothermal carbonization of biomass: a summary and discussion of chemical mechanisms for process engineering," Biofuels, Bioproducts and Biorefining, vol. 4, no. 2, pp. 160-177, 2010.

[11] P. Krammer and H. Vogel, "Hydrolysis of esters in subcritical and supercritical water," Journal of Supercritical Fluids, vol. 16, no. 3, pp. 189-206, 2000.

[12] O. Bobleter, "Hydrothermal degradation of polymers derived from plants," Progress in Polymer Science, vol. 19, no. 5, pp. 797-841, 1994.

[13] M. Sakaguchi, K. Laursen, H. Nakagawa, and K. Miura, "Hydrothermal upgrading of Loy Yang Brown coal—effect of upgrading conditions on the characteristics of the products," Fuel Processing Technology, vol. 89, no. 4, pp. 391-396, 2008.

[14] A. T. Yuliansyah, T. Hirajima, S. Kumagai, and K. Sasaki, "Production of solid biofuel from agricultural wastes of the palm oil industry by hydrothermal treatment," Waste and Biomass Valorization, vol. 1, pp. 395-405, 2010. 
[15] S. M. Heilmann, H. T. Davis, L. R. Jader et al., "Hydrothermal carbonization of microalgae," Biomass and Bioenergy, vol. 34, no. 6, pp. 875-882, 2010.

[16] P. Prawisudha, T. Namioka, and K. Yoshikawa, "Coal alternative fuel production from municipal solid wastes employing hydrothermal treatment," Applied Energy, vol. 90, no. 1, pp. 298-304, 2012.

[17] A. T. Mursito, T. Hirajima, K. Sasaki, and S. Kumagai, "The effect of hydrothermal dewatering of Pontianak tropical peat on organics in wastewater and gaseous products," Fuel, vol. 89, no. 12, pp. 3934-3942, 2010.

[18] A. T. Mursito, T. Hirajima, and K. Sasaki, "Upgrading and dewatering of raw tropical peat by hydrothermal treatment," Fuel, vol. 89, no. 3, pp. 635-641, 2010.

[19] S. M. Heilmann, H. T. Davis, L. R. Jader et al., "Hydrothermal carbonization of microalgae," Biomass and Bioenergy, vol. 34, no. 6 , pp. 875-882, 2010.

[20] A. Hammerschmidt, N. Boukis, E. Hauer et al., "Catalytic conversion of waste biomass by hydrothermal treatment," Fuel, vol. 90, no. 2, pp. 555-562, 2011.

[21] M. Nonaka, T. Hirajima, and K. Sasaki, "Upgrading of low rank coal and woody biomass mixture by hydrothermal treatment," Fuel, vol. 90, no. 8, pp. 2578-2584, 2011.

[22] S. Luo, B. Xiao, Z. Hu, S. Liu, and X. Guo, "An experimental study on a novel shredder for municipal solid waste (MSW)," International Journal of Hydrogen Energy, vol. 34, no. 3, pp. 1270-1274, 2009.

[23] E. Panayotova-Björnbom, P. Björnbom, J.-C. Cavalier, and E. Chornet, "The combined dewatering and liquid phase hydrogenolysis of raw peat using carbon monoxide," Fuel Processing Technology, vol. 2, no. 3, pp. 161-169, 1979. 

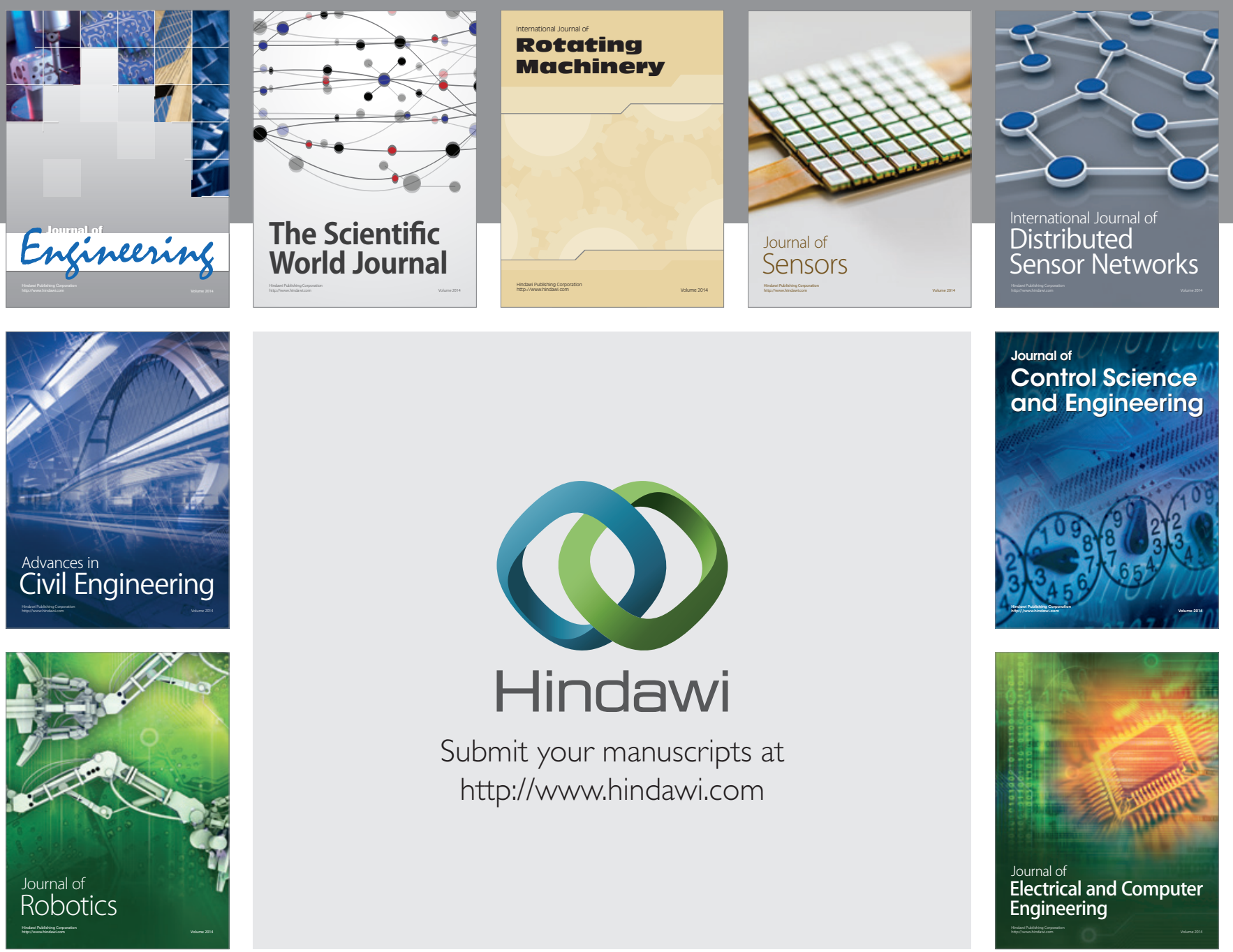

Submit your manuscripts at

http://www.hindawi.com
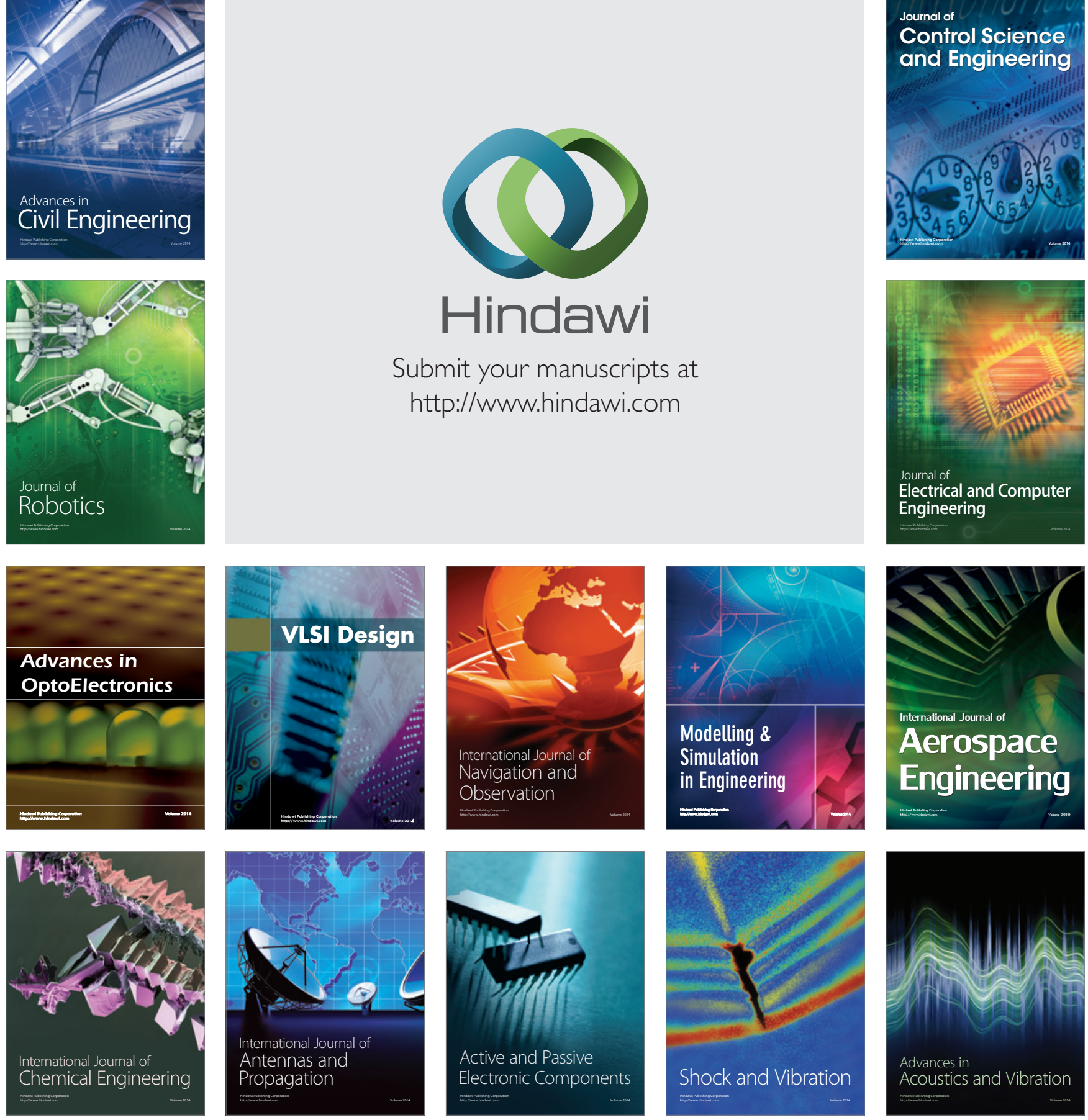